\title{
Incidence and Risk Factors of Surgical Site Infection Following Cesarean Section at Dhulikhel Hospital
}

\section{Shrestha $S,{ }^{1}$ Shrestha $R,{ }^{1}$ Shrestha $B,{ }^{1}$ Dongol $A^{2}$}

\author{
${ }^{1}$ Department of Nursing \\ ${ }^{2}$ Department of Obstetrics and Gynaecology \\ Dhulikhel Hospital-Kathmandu University Hospital \\ Kathmandu University School of Medical Sciences \\ Dhulikhel, Kavre, \\ Nepal
}

\section{Corresponding Author}

Subasna Shrestha

Department of Nursing

Dhulikhel Hospital-Kathmandu University Hospital

Kathmandu University School of Medical Sciences

Dhulikhel, Kavre,

Nepal

E-mail: subasnashrestha@gmail.com

\section{Citation}

Shrestha S, Shrestha R, Shrestha B, Dongol A. Incidence and Risk Factors of Surgical Site Infection Following Cesarean Section at Dhulikhel Hospital. Kathmandu Univ Med J 2014;46(2):113-6.

\section{ABSTRACT}

\section{Background}

Cesarean Section (CS) is one of the most commonly performed surgical procedures in obstetrical and gynecological department. Surgical site infection (SSI) after a cesarean section increases maternal morbidity prolongs hospital stay and medical costs.

\section{Objective}

The aim of this study was to find out the incidence and associated risk factors of surgical site infection among cesarean section cases.

\section{Method}

A prospective, descriptive study was conducted at Dhulikhel Hospital, department of Obstetrics and Gynaecology from July 2013 to June 2014. Total of 648 women who underwent surgical procedure for delivery during study period were included in the study. Data was collected from patient using structred pro forma and examination of wound till discharge was done. Data was compared in terms of presence of surgical site infection and study variables. Wound was evaluated for the development of SSI on third day, and fifth post-operative day, and on the day of discharge.

\section{Results}

Total of 648 cases were studied. The mean age was $24 \pm 4.18$. Among the studied cases $92 \%$ were literate and $8 \%$ were illiterate. Antenatal clinic was attended by $97.7 \%$. The incidence rate of surgical site infection was 82 (12.6\%). SSI was found to be common in women who had rupture of membrane before surgery $(p=0.020)$, who underwent emergency surgery $(p=0.0004)$, and the women who had vertical skin incision ( $p=0.0001)$ and interrupted skin suturing $(p=0.0001)$ during surgery.

\section{Conclusion}

Surgical site infection following caesarean section is common. Various modifiable risk factors were observed in this study. Development of SSI is related to multifactorial rather than one factor. Development and strict implementation of protocol by all the health care professionals could be effective to minimize and prevent the infection rate after caesarean section.

\section{KEY WORDS}

Caesarean section, maternal infection, surgical site infection 


\section{INTRODUCTION}

Motherhood is a life-changing event. Successful physiological, as well as psychological, adjustment will be compromised when the arrival of the baby is coupled with recovery from major abdominal surgery and coping with the pain and discomfort of an abdominal wound. Difficulties are compounded when SSI develops, especially in today's climate of early hospital discharge, which leaves women to cope at home, sometimes with little practical and emotional support. ${ }^{1}$

Caesarean section (CS) is a surgical procedure where a baby is delivered by cutting through the front wall of the abdomen to open the uterus (NHS Direct 2007). The surgeon usually makes a horizontal incision in the woman's lower abdomen, through the abdominal wall and then through the uterus. Cesarean section is one of the most commonly performed surgical procedures in obstetrical and gynecological department. Surgical site infection (SSI) after a cesarean section increases maternal morbidity prolongs hospital stay and medical costs. ${ }^{2}$

The rates of SSI after cesarean section reported in the literature range from $3 \%$ to $15 \%$, depending on the surveillance methods used to identify infections, the patient population, and the use of antibiotic prophylaxis. Maternal infectious morbidity has been shown to be eight-fold higher after cesarean delivery than after vaginal delivery. Due to the worldwide continuous rise in the incidence of cesarean deliveries, the number of women with postpartum infection is expected to increase. The SSI after caesarean section causes physical, psychological and economical burden to woman, her family and to the community. ${ }^{2}$

The incidence of surgical site infection after caesarean section is not known in Dhulikhel hospital. The knowledge of incidence and associated risk factors of SSI after CS will help to increase the awareness among the health care professionals for the prevention of this problem in the hospital

\section{METHODS}

This study was conducted in the department of obstetrics and gynecology, Dhulikhel hospital, Kathmandu University hospital from July 2012 to June 2013.

This is a prospective, descriptive study. Total of 648 women who had undergone cesarean section for delivery during study period were considered as eligible. Patients who were discharged on 3rd day, and who underwent exploratory laparotomy following LSCS were excluded from the study.

Data was collected from patient using special Pro forma and direct observation of wound. Wound observation was done for the development of SSI on third, fifth post operative day and on the day of discharge. All the suspected surgical sites were evaluated irrespective of the day of operation until complete recovery. However, patient who developed infection after discharge were not included in the study due to incompleteness of follow up.

\section{Categorization of surgical site infection for this study.}

Superficial surgical site infection - infection involves only skin or subcutaneous tissue which is treated by dressing and antibiotics.

Deep incisional SSI - infection involves deep soft tissue (e.g. fascial and muscle layers) Or presence of wound dehiscence which requires secondary suturing.

Organ/space SSI - infection involves any part of the anatomy (e.g. organs or spaces), other than the incision, which was opened or manipulated during an operation which required exploration and closing.

Collected data were checked for completeness, entered into the computer and analyzed using SPSS version 16. Data was compared in terms of presence of surgical site infection and study variables. Result of data was calculated in descriptive statistics like mean, frequency and percentage for numerical data and chi-square test was used in inferential statistics in 0.5 level of significance.

\section{RESULTS}

This study has included 648 cases, among which, age 19 and below were 77 ( $11.9 \%)$, age 35 and above were 12 (1.9\%). Out of $648,86.3 \%$ were of age group between 20 to 34 years. The mean age of study patients was 24.3025 (4.18556).

Table 1. Demographic Characteristics of women underwent LSCS

\begin{tabular}{|c|c|c|}
\hline Variables & Frequency & Percent \\
\hline \multicolumn{3}{|l|}{ Age in years } \\
\hline$\leq 19$ & 77 & 11.9 \\
\hline $20-34$ & 559 & 86.3 \\
\hline$\geq 35$ & 12 & 1.9 \\
\hline \multicolumn{3}{|l|}{ Academic background } \\
\hline Literate & 596 & 92 \\
\hline Illiterate & 52 & 8 \\
\hline \multicolumn{3}{|l|}{ Occupation } \\
\hline Housewife & 493 & 76.1 \\
\hline Service & 93 & 14.4 \\
\hline Agriculture & 29 & 4.5 \\
\hline Business & 30 & 4.6 \\
\hline Others & 3 & 0.5 \\
\hline \multicolumn{3}{|l|}{ Antenatal checkup } \\
\hline Yes & 633 & 97.7 \\
\hline No & 15 & 2.3 \\
\hline \multicolumn{3}{|l|}{ Place of ANC $(n=633)$} \\
\hline Dhulikhel Hospital & 423 & 66.8 \\
\hline Outside & 210 & 33.2 \\
\hline
\end{tabular}


Ninety two percent of women were literate and $8 \%$ never attended any formal and informal education. Seventy six percent were engaged in their house hold activities. Total of 97.9 percent did regular ANC check up; 15(2.3) of women had never attended ANC clinic throughout pregnancy. Among ANC attended cases, $66.8 \%$ had attended ANC at Dhulikhel Hospital.

Table 2. Incidence of Surgical site infection

\begin{tabular}{|lc|}
\hline Variables & Number (\%) \\
\hline Infected cases & $82(12.6)$ \\
\hline Non infected cases & $560(86.4)$ \\
\hline Total & $648(100.0)$ \\
\hline
\end{tabular}

Total of $82(12.6 \%)$ women was found to have SSI. Surgical site infection were found to be higher in women who had per vaginal examination more than two to six, however statistically insignificant $(P=0.282)$. SSI was found to be higher in those who had membrane ruptured status before going to surgery $(p=0.020)$; women who underwent emergency LSCS 74 (90.2); who had vertical skin incision ( $p-<0.0001)$ and had interrupted skin suturing $(p-<0.0001)$ during surgery.

\section{DISCUSSION}

Surgical site infection following caesarean section found high rates in this study, which comprises $12.6 \%$. Comparing to other studies conducted in different parts of the world, the SSI following CS was found to be lower in other studies: Oman study $2.66 \%,{ }^{3}$ US 5\%, ${ }^{2}$ Norway $8.3 \%,{ }^{4}$ and UK $9.6 \% .{ }^{5}$ Similar rates were found in other studies conducted in UK $11.2 \%$ and Ethiopia $11.4 \% .{ }^{6,7}$ However, higher rate (16\%) was found in studies conducted in US and India (24.2\%) before intervention. ${ }^{8,9}$ In a retrospective study done in Patan hospital in Nepal, the SSI rate was found to be only $2.7 \%$ which is lower compared to this study. ${ }^{10}$ However, a randomized trial comparing skin closure in cesarean section conducted in Chitwan showed that, overall wound complications rate for the entire cohort was found $15.2 \%{ }^{11}$

The risk of developing SSI after C-section is multi-factorial and has been found to be influenced by the following factors in this study: emergency surgery, membrane rupture before surgery, vertical skin incision and interrupted skin suturing which were found statistically significant.

The ratio of elective and emergency surgery rate in this study observed was 1:3.5. In our study, more incidence of SSI was observed in those who had undergone emergency LSCS (90.2\%) compared to elective LSCS (9.8\%) and was statistically significant $(p=0.007)$. A study conducted in India also revealed that Emergency caesarean section predisposes more to SSI as compared to elective (80.16\%). 9 Similar findings were identified in a study conducted in
Table 3. Incidence of surgical site infection and associated risk

\begin{tabular}{|c|c|c|c|}
\hline Variables & Frequency & $\begin{array}{l}\text { SSI cases } \\
\text { Number (\%) }\end{array}$ & $P$ value \\
\hline \multicolumn{4}{|l|}{ ANC attended } \\
\hline Yes & 633 & $79(96.3)$ & 0.387 \\
\hline No & 15 & $3(3.7)$ & \\
\hline \multicolumn{4}{|l|}{ Types of surgery } \\
\hline Elective & 144 & $8(9.8)$ & \\
\hline Emergency & 504 & $74(90.2)$ & 0.0004 \\
\hline \multicolumn{4}{|l|}{ Rupture of membrane } \\
\hline No & 183 & $32(39.0)$ & \\
\hline Yes & 465 & $50(61.0)$ & 0.020 \\
\hline \multicolumn{4}{|l|}{ Per- vaginal examination } \\
\hline Not done & 42 & $2(2.4)$ & \\
\hline 2 to 6 times & 569 & $75(91.5)$ & 0.282 \\
\hline$>6$ times & 37 & $5(6.1)$ & \\
\hline \multicolumn{4}{|l|}{ Types of incision (skin) } \\
\hline Vertica & 251 & $50(61.0)$ & $<0.0001$ \\
\hline Horizontal & 397 & $32(39.0)$ & \\
\hline \multicolumn{4}{|l|}{ Types of suturing (skin) } \\
\hline Interrupted & 326 & $64(78.0)$ & $<0.0001$ \\
\hline Subcuticular & 322 & $18(22.0)$ & \\
\hline
\end{tabular}

Ethiopia where emergency surgery had two times increased risk of surgical site infection (11.9\% vs $5.4 \%$ ) than elective cases. ${ }^{7}$ This finding could be attributable to the fact that in emergency cases membrane rupture and multiple vaginal examinations are frequent. There is also increased risk of bacterial contamination or breaks in sterile technique or lack of timely antibiotic prophylaxis. These findings have been reported in studies conducted in India, ${ }^{9}$ Ethiopia and MG martens. ${ }^{7,12}$

The length of time between rupture of the membranes and surgery also showed statistically significant risk for surgical site infection ( $P=0.02)$. Study conducted in Oman revealed four-fold increased risk in the rate of PROM among the case group compared to the controls. They found association between PROM and wound infections highly significant $(P<0.001) .^{3}$ In the study done in Tanzania, rupture of membranes prior to surgery lasting 8 hours or longer, (HR $=2.7 ; 95 \% \mathrm{Cl}=1.3-5.8 ; \mathrm{p}=0.011)$ and 3 or more vaginal examinations $(\mathrm{HR}=3.3 ; 95 \% \mathrm{Cl}=1.7-6.5 ; \mathrm{p}=0.001)^{13}$ were found to be significant risks for SSI development. Once the membrane is ruptured the amniotic fluid has increased chance to get infected induced by multiple vaginal examinations. It is thought that the non-sterile amniotic fluid may act as a transport medium by which bacteria come into contact with the uterine and skin incision leading to chorioamnionitis and its sequelae. These findings were supported in other studies. $3,5,12,13$ 
In our study, increased rate of SSI was observed in women who were given vertical incision which was statistically significant $(p=0.0001)$. In a study conducted in India, type of skin incision had been found to be a risk factor for developing SSI. They found up to $19.8 \%$ SSI associated with vertical skin incision on univariate analysis. ${ }^{9}$ Vertical incision was significantly found to predict SSI; women with vertical skin incisions had a 3.6 fold risk of developing a SSI compared to those with transverse skin incision. ${ }^{13}$ Over all incidence of wound complications in Pfannenstiel group was $13.33 \%$ and in midline vertical group it was $26.66 \% .{ }^{14}$ Study conducted in New York based hospital found a significantly greater incidence of wound complications (35\% compared with $9 \%$ ) in women with vertical skin incisions. ${ }^{15}$ Infection also occurred more frequently following a vertical skin incision (15.3\% compare with $9.1 \%$ of transverse incision). The difference was significant $(p<0.05) .{ }^{16}$ A transverse incision has less chance of wound dehiscence. ${ }^{17}$

In our study, the SSI was also found to be significantly higher $(P=<0.0001)$ in those where interrupted suturing $(78 \%)$ was employed whereas, women who had intracutaneous suture had less SSI (22\%). Study conducted in UK revealed the lowest SSI rate in patients where a continuous suture had been used; $1.3 \%$ in 2009 , to $6.7 \%$ in 2010 and $10.7 \%$ in $2011 .{ }^{18}$ The choice of subcuticular suture rather than staples to close the surgical site is associated with a significantly lower incidence of infection. ${ }^{1,6}$ Subcuticular sutures buried in the wound were found less likely to cause infection. ${ }^{19}$

Our study has some limitations. Some of the cases during the study period were not followed up which could likely influence the calculated rate of surgical site infection. The various other potential risk factors that can cause SSI could not be assessed in this study, such as : obesity, increased $\mathrm{BMI}$, wound contamination grade, ASA grade, duration of surgery, amount of blood loss.

\section{CONCLUSION}

SSI after caesarian section is a common problem in most of the tertiary care hospitals. The risk of developing SSI after C-section is multi-factorial and has been found to be most commonly influenced by the following factors in this study: emergency surgery, membrane rupture before surgery, vertical skin incision and interrupted skin suturing.

Therefore, increased awareness on these risk factors, development and strict implementation of protocol should be done by all the health care professionals in order to minimize and prevent the infection rate after caesarean section.

\section{REFERENCES}

1. Gould D. Caesarean section, surgical site infection and wound management. Nursing Standard 2006 Nov;21(32):57-66.

2. Olsen MA, Butler AM, Willers DM, Devkota P, Gross GA and Fraser VJ. Risk factors for surgical site infection after low transverse cesarean section. Infect Control Hosp Epidemiol 2008;9:477-84.

3. Dhar H, Busaidi Al, Rathi B, Nimre A E, Sachdeva V and Hamdi I. A Study of Post-Caesarean Section Wound Infections in a Regional Referral Hospital, Oman. Sultan Qaboos University Med J 2014 May; (14)2:e211-21.

4. Eriksen $H M$, Sæther $A R, L \varnothing$ wer $H L$, Vangen $S$, Hjetland R, Lundmark $H$, Aavitsland P. Infections after caesarean sections. Journal of Norwegian Medical Association. Tidsskr Nor Legeforen 2009;129:618-22.

5. Wloch C, Wilson J, Lamagni T, Harrington P, Chalett A, Sheridan E. Risk factors for surgical site infection following caesarean section in England: result from a multicentre cohort study; BJOG An international Journal of Obstetrics and gynaecology 2012;119:1324-1333.

6. A Johnson, D young, J Reilly. Caesarean section surgical site infection Surveillance. Journal of hospital infection 2006;64:30-35.

7. Amenu D, Belachew T and Araya F. Surgical site infection rate and risk factors among obstetric cases of Jimma University specialized hospital, Southwest Ethiopia. Ethiop Journal of Health Science 2011 July;21(2).

8. Cocoran S, Jackson V, Smith C S, Loughrey J. Kenna MC, Cafferkey M. Surgical site infection after cesarean section: Implementing 3 changes to improve the quality of patient care. Dublin, Ireland. American Journal of Infection Control 2013; 41:1258-63

9. De D, saxena S, Mehata G, Yadav R, and Dutta R. Risk factor analysis and microbial etiology of surgical site infections following lower segment caesarean section. International Journal of Antibiotics 2013; Volume 2013, Article ID 283025, 6 pages

10. Pandit A. Sharma P and Yangzom K. Incidence of caesarean wound infection in Patan hospital, Nepal. Journal of Nepal Medical Association 2003;42:280-3.

11. Shrestha A, Napit J, Neupane B and Sedhain LB. A randomized tria comparing skin closure in cesarean section: Interrupted suture with nylon vs subcutucular suture with No 1 polyfilament. JNHRC 2013 Sept;11(3)

12. Martens M G, Kolrud B L, Faro S, Maccato M, and Hammill H. Developmwnt of wound infection or separation after cesarean delivery: prospective evaluation of 2431 cases. Journal for reproductive medicine for obstetrician and gynaecologist 1995;40(3):171-5.

13. Mpogoro et al. Incidence and predictors of surgical site infections following caesarean sections at Bugando Medical Centre, Mwanza, Tanzania. Antimicrobial Resistance and Infection Control 2014; 3:25.

14. Thawal A Y, and Waghmare M. A Comparative Study Between Midline Vertical and Pfannestiel incision in lower Segment Caesarean Section With Reference to Wound Complications. Indian Journal of applied research 2014;4(10).

15. Wall DP, Deucy E E, Glantz and Pressman E K. Vertical Skin Incisions and Wound Complications in the Obese Parturient, The American College of Obstetricians and Gynecologists 2003 Nov;102(5), Part1.

16. Webster J. Post caesarean wound infection: A review of the risk factors. Aust NZ Journal of Obstetric and gynaecology 1988:201.

17. Killian CA, Graffunder EM, Vinciguerra TJ, Venezia RA. Risk factors for surgical-site infections following cesarean section. Infect Control Hosp Epidemiol 2001;22:613-17.

18. Caesarean section surgical site infection surveillance. Wexford general hospital. 2009 to 2011 comparative report.

19. Wetter LA, Dinnee MD, Leitt MD, Motton RW. Controlled trial of polyglycolic acid versus catgut and nylon for appendectomy wound closure. British Journal of Surgery 78,8, 985-987. 